\title{
Mathematical Model of the Fixture Flexibility Impact on Machining Accuracy of Levers
}

\author{
Vitalii Ivanov ${ }^{1, *}$, Ivan Dehtiarov ${ }^{1}$, and Ivan Pavlenko ${ }^{2}$ \\ 'Sumy State University, Faculty of Technical Systems and Energy Efficient Technologies, Department of Manufacturing Engineering, Machines and Tools, \\ 2 Rymskogo-Korsakova St., Sumy 40007, Ukraine \\ ${ }^{2}$ Sumy State University, Faculty of Technical Systems and Energy Efficient Technologies, General Mechanics and Machine Dynamics, 2 Rymskogo- \\ Korsakova St., Sumy 40007, Ukraine
}

\begin{abstract}
Flexible fixtures increasingly acquire an extension in up-to-date manufacturing engineering, albeit an attempt to determine the impact of the flexibility on the fixture accuracy parameters was not performed in previous research. The aim of this work is determination the opportunity to provide dimension accuracy for lever machining in the high-flexible fixture. Experimental values of displacements of the elements of the system "fixture - workpiece" for the different levels of fixture flexibility were obtained by means of finite elements analysis. On the example of levers machining it was stated that increasing the fixture flexibility allows receiving in a certain range the required dimension accuracy of the parts. Displacements were used for obtaining the mathematical model of the fixture accuracy depending on fixture flexibility. This model in case of levers machining describes by nonlinear function of evaluated flexibility indicators. The method of quasilinear evaluation of the parameters was used for identification the design flexibility by minimization of the total square deviation using the iteration procedure.
\end{abstract}

Keywords: complex part, lever, mathematical model, deviation, multiaxis machining, flexibility, system "fixture -workpiece", stiffness.

\section{Introduction}

Up-to-date manufacturing is characterized by producing of the multiproduct parts due to including the medium-batch and small-batch manufacturing approximately on $75 \%$. Increasing the product range needs to complicate of design work for tooling manufacturing, especially fixtures. Such manufacturing conditions require the frequent changeovers for machining the other batch that leads to development and implementation of flexible fixtures, which are capable for readjustment in a specified size range of the part by adjusting the locatingand-clamping elements [1]. Increasing the competitiveness of the manufacturing production at small enterprisers is provided by reducing the costs for design and manufacturing of tooling. This is especially essential for drilling, milling, and boring operations for complex parts machining that requires a large number of setups.

In this context the intensification of manufacturing has the increasing relevance, particularly for manufacturing processes. This foresees reducing the cost of the machining time by decreasing the auxiliary time, which becomes possible in 
carrying out the surface machining in one setup. This ways form the actual problem due to a highly competitive market, multiproduct manufacturing and capabilities of the up-to-date metal-cutting machine tools [1].

\section{Literature Review}

An effective solution for up-to-date manufacturing engineering is related to using flexible fixtures with spreading manufacturing capabilities, which allows reducing the preparatory time for readjustment, so contributes increasing an efficiency of machine tools using. The developed design solutions for locating the prismatic parts on the plane $[2,3]$, plane and two holes $[4,5]$, coordinate angle [6], as well as for locating the rotary parts on external [7] and internal [8-10] cylindrical surfaces confirmed the high efficiency in up-to-date manufacturing engineering $[1,11$, 12].

A process engineer must possess the information about compliance the fixture accuracy on a certain manufacturing operation due to the rational using the resources. This is necessity in order to not assign the high-accuracy fixture for rough operations and conversely, because the cost of fixture for machining at finish operation is much higher. In other words, on other equal conditions it's necessary to choose exactly the design, which will provide the machining accuracy given by a designer. The main works of other researchers, related to the subject of fixture accuracy and flexibility are stated below.

Fundamental analysis of the importance of flexibility for up-to-date manufacturing engineering is represented in previous research. Specifically, the economic, organizational and manufacturing aspects including the information for variety of definitions of term "flexibility" were shown in the works [13-24]. Principally, several types of flexibility were identified, and the relationship between them was graphically represented in the work [13]. This is important to increase the manufacturing system flexibility, speed of decision making and ability of the equipment to adjustment within transition to new production. Thus, it's necessary to minimize the time spending and satisfy the market by competitive production.

Beach et al. [25] considered the flexibility in the context of expanding the production capacity and increasing the production competitiveness. There were considered 11 existing types of flexibility and were determined the relationship between them. The feature of the work of Pérez Pérez et al. [26] is systematization and consideration of the main types of flexibility and comparison of their definitions in terms of hierarchy and strategy.

Chambers [27], Gaimonand and Singhal [28] Deshmukhetal et al. [29] and Calinescuetal et al. [30] emphasize that the life cycle of production has significantly reduced that leads to a change of dedicated equipment to flexible one, so this is a guarantee for flexibility increasing in general.

Correa [31] was shown the correlation between the size, frequency of product range changing, production speed and flexibility as a flowchart. He proposed the theory that timely manufacturing with uncertainty the manufacturing process must be flexible and has quickly response on changes using the monitoring and forecasting tools.

In research of Pelaez and Ruiz [32] the flexibility is represented as a strategic concept in decision making process, the outcomes of which allow giving rapid and efficient response on the requirements of the national and internationa markets.

Benjaafar and Ramakrishman [33] are differently consider the terms of product flexibility and process flexibility. Product flexibility relates to factory's options and is regulated within the enterprise. Process flexibility is determined and depends on the industrial process characteristics, which are constantly in dynamic state, because for specified manufacturing time it's necessary to rapid respond for change of each component that is included to hierarchical structure. Both of these terms are mutually independent, albeit they reach to common goal - increasing the flexibility of the manufacturing system in general.

Kaschel and Sánchez y Bernal [34] proposed a model of the fuzzy logic and mathematical programming to determine the structural and behavior problems occurring in a manufacturing system. These approaches allow to operatively responding on unexpected changes in market requirements arising in up-to-date industrial environment. Due to above-mentioned the use of flexible fixtures is a reserve for improving the competitiveness in up-to-date industrial environment. However, until nowadays it's 
survived the hypothesis that increasing the flexibility reduces the accuracy and productivity of machining, so it's need to verify the possibility of achieving the accuracy of designed parameters for highly flexible-fixtures.

Kumbhar et al. [35] stated by means of created finite elements model of the system "fixture workpiece" that increasing the friction coefficient provides higher stiffness of the fixture parts in applying loading, and decreasing the roughness of the contact surfaces leads to increasing the contact stiffness and reduces related contact deformations.

Papastathis et al. [36] represented the methodology for determining the optimal position of the clamping elements during the thin-walled parts machining. This allows reducing the maximum deformations and improving an adhesion for deformed surfaces during machining. In this case, the clamping elements on the model "fixture - workpiece" were represented as adjustable.

Tadich et al. [37] considered clamping the workpieces with complex geometry by using tapered wedges that allowed carrying out the parts machining from the five sides with one side locating. The results showed that stiffness of the system "fixture - workpiece" is insufficient for this locating method. In further research using the technological holes is proposed for redistribute the clamping force and increase loading from forces and moments.

Kang et al. [38] developed a technique for analysis of the fixture stability, which is realized in computer-aided fixture design system CAFixDV. On the base of created kinematic model of the system "fixture - workpiece" the problems of fixture equilibrium state are formulated and impact of the clamping order on fixture stiffness is investigated. Also, the stiffness matrix is developed for joint the external forces with related displacements, which can be evaluated by using the linear regression model.

Asante [39] investigated the impact of fixture stiffness and cutting conditions on the workpiece stability. This technique was used as a foundation for choosing the appropriate fixture among several alternatives by using the analytical approach. The eigenvalues of displacements for the different cutting conditions were detected during research, which allowed reducing the maximum displacements on $68 \%$ by changing the cutting conditions.

The matrix that taking into account the relationship between the workpiece locating error and deviation in the mispositioning and sizing error of clamping surfaces of the fixture was developed by Wang [40]. In this case, the features of fixture manufacturing and clamping points were taken into account for investigation of the impact on machining accuracy. The optimal design of the fixture was proposed for minimizing the machining error and decreasing an excessive accuracy of separate elements, that was shown as the example for the turbine wings.

Valandi et al. [41] completed the analysis of deflected mode of the dedicated fixture, which consists of a minimum number of parts. In this case, the required machining accuracy was achieved, but research of flexible fixtures has not performed. The above-mentioned works consider the concept of flexible manufacturing systems and machining accuracy, which are expressed in the terms of displacements of elements of the system "fixture - workpiece". However, the necessary correlation between these both parameters is not detected. Therefore, solving the problem of rational using the fixture resource requires determination of flexibility and accuracy by using the functional dependence.

The aim of this research is establishing the machining capabilities in the high-flexible fixture while compliance of the dimension accuracy by using the methods of mathematical modeling in the example of the fixture for levers machining. To achieve this aim the research problems are formulated:

$\checkmark$ determination of deformations of the system "fixture - workpiece" in fixtures with different levers of flexibility;

$\checkmark$ formulating the hypothesis for depending the machining accuracy on the level of flexibility of the fixture;

$\checkmark$ development and verification of the mathematical model "accuracy - flexibility".

\section{Results and Discussion}

3.1 Fixture Design

The research object is the fixture for levers machining (Fig. 1). Analysis of the deflected 
mode was analyzed in previous research. Eigenfrequencies of oscillations of the system "fixture - workpiece", as well as dynamic stiffness and amplitudes of oscillations of elements of the system "fixture - workpiece" were determined in the work [43].

The adjustable locating-and-clamping module [42] for machining the levers of different standard sizes within specification is developed. It allows reducing the changeover time and providing the tool accessibility of the machining surfaces. The represented configuration is intended for locating the levers of a range of diameters of central boss 26-42 $\mathrm{mm}$ and thickness of arms 13-21 mm, which is realized by adjusting the screw mechanisms. The adjustable locating-and-clamping module may be located either on the machine tool table or on the baseplate, which is the element of different sets of the modular fixtures. This design solution in combination with the rotary table of the machine tool allows carrying out all the drilling, milling, and boring operations at one setup CNC multiaxis machining operation, performed on the CNC machining center. The level of flexibility of the proposed fixture $\mathrm{G}=0,9$ is determined within the previous research for number of locating standard lever sizes 10 units (Table 1). Due to proposed classification of the adjustment levels the fixture is categorized to the adjustable.

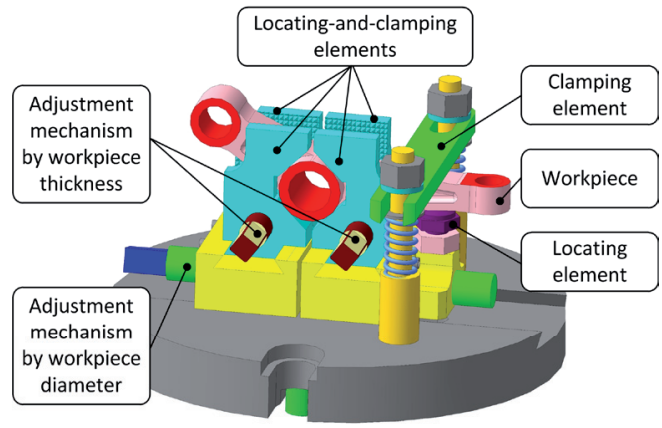

Fig. 1: The fixture for levers machining.

However, for reach the main aim it's necessary to have an opportunity for varying of the level of flexibility and controlling the fixture displacements. This becomes possible due to the gradual restriction of capability for movement of the separate fixture elements by their merging together, as well as gradual transformation of the flexible fixture to the dedicated one. The element of the system "fixture - workpiece" with the maximum value of total displacement $0,143 \mathrm{~mm}$ is chosen as a reference point [43]. It corresponds to the boss face of auxiliary hole parallel to the main one in drilling step. The stages for restriction of capabilities for movement of the fixture elements, number of locating standard sizes, related levels of flexibility and readjustment levels are represented in Table 1.

\subsection{Fixture Flexibility}

The target function for determining the fixture flexibility has the following form [1]:

$$
G=\left(1-\frac{1}{n}\right) \cdot \frac{1}{1+\sum_{i=1}^{n} t_{c h i} /\left(\sum_{i=1}^{n} t_{i} \cdot N_{i}\right)},
$$

where $n$ - number of standard sizes of the machined parts; $t_{c h i}$ - the changeover time of the fixture for machining the part of $i$-th standard size; $t_{i}$ - the machining time for machining the part of $i$-th standard size; $N_{i}$ - the batch size of $i$-th standard size.

The components $t_{c h i}, t_{i}, N_{i}$ remain constant, and the right multiplier is the constant unit, so the level of flexibility $G$ will be depended only on number of standard sizes for the parts located in the fixture that finally makes the greatest impact on flexibility in terms of medium-batch manufacturing.

Further restriction of movement of the fixture elements is irrational, because it will not change the level of flexibility. Consequently, taking into account the base fixture design, there are 4 different levels of flexibility, which are correspond to three levels of adjustment and are the fundamental for describing the mathematical model.

\subsection{Formulation of the Hypothesis}

The constraints, which are not contrary to physical laws, describe below:

$\checkmark$ the level of flexibility is varying in the range $0 \leq G \leq 1$;

$\checkmark$ displacement of the elements of the dedicated fixture $\Delta 0=\Delta(0)$;

$\checkmark$ absolutely flexible fixture has the displacements, which asymptotically tend to infinity: $\Delta(1) \rightarrow \infty$;

$\checkmark$ increasing of the flexibility leads to increase the displacement: $\frac{\partial \Delta}{\partial G}>0$. 
Table 1: The fixture for levers machining with variable flexibility.

\begin{tabular}{|c|c|c|c|c|c|}
\hline $\begin{array}{l}\text { Fixtures with clamping } \\
\text { charts of the fixture } \\
\text { elements }\end{array}$ & Fixed parts and contact type & $\begin{array}{l}\text { Number of } \\
\text { standard sizes }\end{array}$ & $\begin{array}{l}\text { Level of } \\
\text { flexibility }\end{array}$ & $\begin{array}{l}\text { Adjustment } \\
\text { level }\end{array}$ & $\begin{array}{l}\text { Displacement of the } \\
\text { element, } \mathrm{mm}\end{array}$ \\
\hline & - & 10 & 0,9 & adjustable & 0,143 \\
\hline & $\begin{array}{c}\text { parts } 1 \text { and } 2 \text { - contact } \\
\text { Bonded }\end{array}$ & 5 & 0,8 & $\begin{array}{l}\text { partially } \\
\text { adjustable } \\
\text { of 3rd level }\end{array}$ & 0,143 \\
\hline & $\begin{array}{c}\text { parts } 1 \text { and } 2 \text { - contact } \\
\text { Bonded }\end{array}$ & & & & \\
\hline & $\begin{array}{c}\text { parts } 3 \text { and } 4 \text { - contact } \\
\text { Bonded }\end{array}$ & 3 & 0,67 & $\begin{array}{l}\text { adjustable } \\
\text { of } 3 \text { rd level }\end{array}$ & 0,074 \\
\hline & $\begin{array}{c}\text { parts } 1 \text { and } 2 \text { - contact } \\
\text { Bonded }\end{array}$ & \multirow{3}{*}{1} & \multirow{3}{*}{0} & \multirow{3}{*}{$\begin{array}{c}\text { non- } \\
\text { adjustable }\end{array}$} & \multirow{3}{*}{0,067} \\
\hline & $\begin{array}{c}\text { parts } 3 \text { and } 4 \text { - contact } \\
\text { Bonded }\end{array}$ & & & & \\
\hline$\frac{1}{\text { Banded }}$ & $\begin{array}{c}\text { parts } 1 \text { and } 5 \text { - contact } \\
\text { Bonded }\end{array}$ & & & & \\
\hline
\end{tabular}

Above-mentioned constraints are graphically represented in Fig. 2.

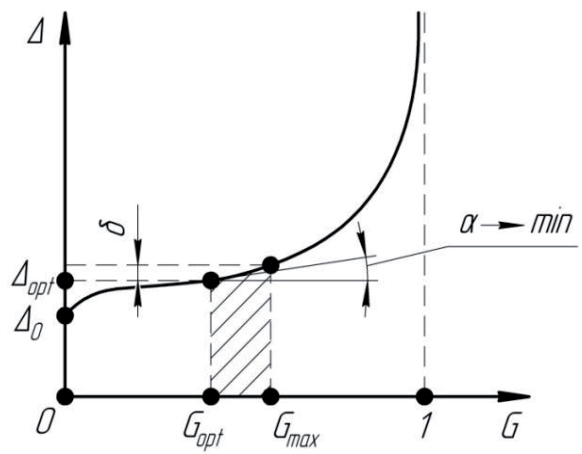

Fig. 2: Graphical representation of the hypothesis "accuracy flexibility".

A similar function can be described by the following dependence:
$\Delta(G)=\frac{\Delta_{0}}{\left(1-G^{m}\right)^{n}}$

where $\Delta_{0}=\Delta(0)$ - displacement of the elements of the dedicated fixture with the level of flexibility $G=0 ; m, n$ - exponents of the functional dependence, which are determined by the experimental data.

\subsection{Mathematical Model}

For minimizing the approximation error for experimental points $\left(G i, \Delta_{i}\right)$ by the analytical dependence (2) the total square deviation is determined:

$R_{0}(m, n)=\sum_{i=1}^{N}\left[\frac{\Delta_{0}}{\left(1-G_{i}^{m}\right)^{n}}-\Delta_{i}\right]^{2} \rightarrow \min .(3)$

The problem of determining the parameters $m$, $n$ within the condition (3) is nonlinear and does not have an exact analytical solution, so it will be 
reduced to quasilinear model relatively to $m$ and $n$ alternatively. For the further actions the algebraic transformations of the equation (2) is performed for experimental points $\left(G_{i}, \Delta_{i}\right)$ :

$$
\begin{aligned}
& 1-G_{i}^{m}=\left(\frac{\Delta_{0}}{\Delta_{i}}\right)^{\frac{1}{n}}, \\
& \left(1-G_{i}^{m}\right)^{n}=\frac{\Delta_{0}}{\Delta_{i}} .
\end{aligned}
$$

Performing logarithm procedure and determining the total square deviation for each of equations (4) and (5) it can be obtained:

$$
\begin{array}{r}
R_{1}(m, n)= \\
\sum_{i=1}^{N}\left\{m \cdot \ln G_{i}-\ln \left[1-\frac{1}{\left(\frac{\Delta_{i}}{\Delta_{0}}\right)^{\frac{1}{n}}}\right]\right\}^{2} \rightarrow \min ,(6) \\
R_{2}(m, n)= \\
\sum_{i=1}^{N}\left[n \cdot \ln \left(1-G_{i}^{m}\right)+\ln \frac{\Delta_{i}}{\Delta_{0}}\right]^{2} \rightarrow \min .(7)
\end{array}
$$

Evaluated parameters $m, n$ are determined by the condition of equality to zero the gradient of the total square deviation:

$$
\begin{aligned}
& \frac{\partial R_{1}}{\partial m}= \\
& \sum_{i=1}^{N} 2 \cdot\left\{m \cdot \ln G_{i}-\ln \left[1-\frac{1}{\left(\frac{\Delta_{i}}{\Delta_{0}}\right)^{\frac{1}{n}}}\right]\right\} \cdot \ln G_{i}=0, \\
& \frac{\partial R_{1}}{\partial m}= \\
& \sum_{i=1}^{N} 2 \cdot\left\{m \cdot \ln G_{i}-\ln \left[1-\frac{1}{\left(\frac{\Delta_{i}}{\Delta_{0}}\right)^{\frac{1}{n}}}\right]\right\} \cdot \ln G_{i}=0 .
\end{aligned}
$$

Obtained equations (8) and (9) are linear relatively to $m$ and $n$, and the corresponding values are:

$$
\begin{gathered}
m=\frac{\sum_{i=1}^{N} \ln G_{i} \cdot \ln \left[1-\frac{1}{\left(\frac{\Delta_{i}}{\Delta_{0}}\right)^{\frac{1}{n}}}\right]}{\sum_{i=1}^{N} \ln ^{2} G_{i}} \\
n=-\frac{\sum_{i=1}^{N} \ln \left(1-G_{i}^{m}\right) \cdot \ln \frac{\Delta_{i}}{\Delta_{0}}}{\sum_{i=1}^{N} \ln ^{2}\left(1-G_{i}^{m}\right)}
\end{gathered}
$$

The combination expressions (10)-(11) forms a system of two nonlinear algebraic equations of $m$ and $n$ :

$\left\{\begin{array}{l}m=m(n) ; \\ n=n(m),\end{array}\right.$

which can be solved by using the simple iteration procedure by obtained experimental data of the values of the levels of flexibility and displacements. The flowchart of iteration procedure is represented in Fig. 3.

The iteration procedure and evaluated exponents $m=5,011$ and $n=1,199$ are realized by using the system of mathematical algebra MathCAD 14. Consequently, the target function of determining the fixture accuracy depending on the level of flexibility describes by the dependence:

$\Delta(G)=\frac{\Delta_{0}}{\left(1-G^{5,011}\right)^{1,199}}$.

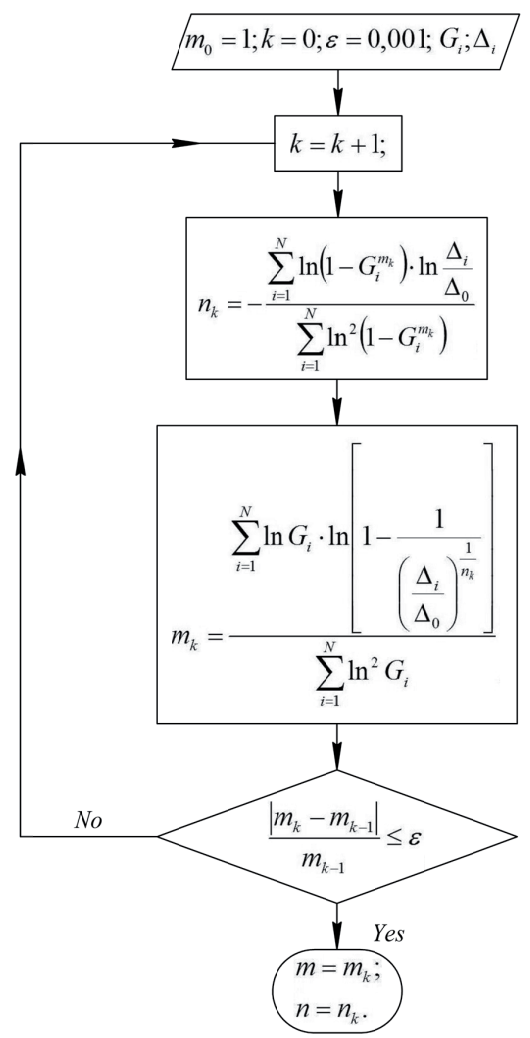

Fig. 3: Flowchart of iterative procedure for finding the coefficients $m$ and $n$. 
Thereby, due to the dependence (13) the several fixture configurations with the different levels of flexibility may be corresponding to the condition of reaching the required accuracy. Two approaches has been applied for determining the flexibility range $\left[G_{\min }, G_{\max }\right.$ ] for providing the predetermined (optimal) accuracy:

1. In case of $\mathrm{m} \geq 1$ it's taken $G_{\min }=0$ corresponding to dedicated fixture, and $G_{\max }$ is determined by the condition:

$$
\Delta\left(G_{\max }\right)=(1+\delta) \Delta_{0}
$$

where $\delta$ - an acceptable level of accuracy changes of the fixture in comparison with dedicated fixture (Fig. 2).

Corresponding expression has been determined from the equation (14) by using the dependence (2):

$$
G_{\max }=\left[1-\frac{1}{(1+\delta)^{\frac{1}{n}}}\right]^{\frac{1}{m}} .
$$

2. In case of $m<1$ the optimal flexibility is determined by the minimum angle $\alpha_{\min }$ of inclination of the tangent to the graph of the function $\Delta(G)$ (Fig. 2). The tangent of this angle based on the dependence (2) is:

$$
\operatorname{tg} \alpha=\frac{\partial \Delta}{\partial G}=\frac{m \cdot n \cdot \Delta_{0} G^{m-1}}{\left(1-G^{m}\right)^{n+1}} \rightarrow \min .
$$

The minimum value of the angle $\alpha_{\min }$ is determined by equation:

$$
\frac{\partial(\operatorname{tg} \alpha)}{\partial G}=\frac{\partial}{\partial G}\left[\frac{m \cdot n \cdot \Delta_{0} G^{m-1}}{\left(1-G^{m}\right)^{n+1}}\right]=0 .
$$

Identical mathematical transformations allow describing

$$
G_{o p t}=\left[\frac{1-m}{1+m \cdot n}\right]^{\frac{1}{m}},
$$

and the corresponding optimal accuracy due to formula (2) is:

$$
\Delta_{\text {opt }}=\Delta\left(G_{o n m}\right)=\Delta_{0} \cdot\left[\frac{1+m \cdot n}{m(n+1)}\right]^{n} .
$$

\subsection{Mathematical Model Analysis and Modeling}

Evaluated values of displacements and corresponding levels of flexibility obtained by formula (13) were correlated to the experimental

\begin{tabular}{|c|c|c|c|}
\hline $\begin{array}{l}\text { Level of } \\
\text { flexibility G }\end{array}$ & $\begin{array}{l}\text { Experimental } \\
\text { values of } \\
\text { displacements } \\
\Delta \mathrm{E}, \mathrm{mm}\end{array}$ & $\begin{array}{l}\text { Theoretical } \\
\text { values of } \\
\text { displacements } \\
\Delta \mathrm{T}, \mathrm{mm}\end{array}$ & $\begin{array}{l}\text { Relative } \\
\text { error, \% }\end{array}$ \\
\hline 0 & 0,067 & 0,067 & 0 \\
\hline 0,67 & 0,074 & 0,079 & 6,6 \\
\hline 0,8 & 0,143 & 0,107 & 24,5 \\
\hline 0,9 & 0,143 & 0,189 & 33,7 \\
\hline
\end{tabular}
data for verifying the accuracy of the mathematical model (13) (Table 2). The relevant graphical representation is shown in Fig. 4.

Table 2: Comparing the results of the experimental data and mathematical model.

Comparative graph of the experimental and theoretical values of displacement confirms the credibility of the received mathematical model, because the nature of the points placement is the same. The errors between theoretical and experimental data for displacements are from 6,6 to $33,7 \%$, moreover for the level of flexibility in the range $0 \div 0,7$ the error does not exceed $10 \%$. After exceeding $G \geq 0,7$ the error is increasing, that may be explained by design specificity for the fixture and chosen control point for displacement determining. Surely, constructive restriction of the movement capability for the separate fixture elements for varying the flexibility degree does not impact on displacement for the certain cases. As shown in Table 2 there are similar displacements $\Delta=0,143 \mathrm{~mm}$ for $\mathrm{G}=0,8$ and $\mathrm{G}=0,9$. Alternatively, in the range of $\mathrm{G} \geq 0,7$ the theoretical values of displacements exceed the real ones, that is the additional reserve to take into account other manufacturing errors, which can occur during machining that is especially important for the high-flexible fixtures.

The obtained mathematical model completely corresponds to the physical meaning for depending the accuracy on the level of fixture flexibility $G$, and may be used for further implementation of such dependences for other fixtures, which will be differed only by exponents $m$ and $n$. 


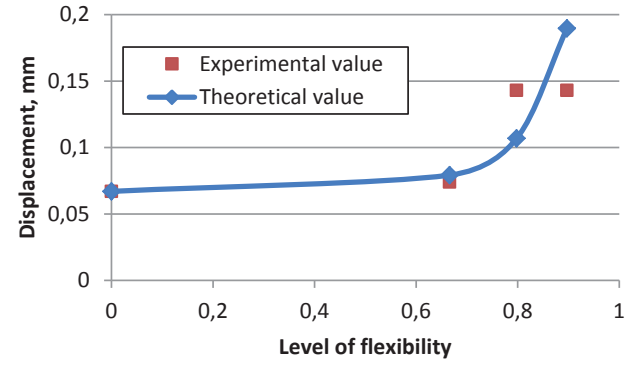

Fig. 4: Approximation of the experimental data by theoretical curve.

\section{Conclusion}

1. Conducted research of deflected mode at the most loaded step by changing the level of fixture flexibility is showed that the displacements change disproportionately. It may be explained by design specificity for the fixture and chosen control point for displacement determining. Restriction of the movement capability for the separate elements of the fixture for varying the flexibility degree in the certain cases is not impact to the value of displacement, particularly, there are similar displacements $\Delta=0,143 \mathrm{~mm}$ for $G=0,8$ and $G=0,9$.

2. The analytical hypothesis is formed on the basis of the experimental values of displacements of the control point for the different levels of flexibility, and the related mathematical model as a power function is obtained. This model consider the value of displacements of the dedicated fixture and the level of flexibility of the investigated fixture as the alternative in manufacturing process.

3. The method for identification of the parameters of the nonlinear mathematical model "accuracy flexibility" on the result of numerical experiment is proposed and realized by transformation to quasilinear regression model.

4. Analysis of the mathematical model is confirmed absolutely compliance with the physical meaning of the dependence of fixture accuracy $\Delta$ from the level of flexibility $G$. The errors between theoretical and experimental data for displacements are from 6,6 to $33,7 \%$, moreover for the level of flexibility in the range $0 \div 0,7$ the error does not exceed $10 \%$. After exceeding $G \geq 0,7$ the error is increasing, but the theoretical values of displacements exceed the real ones, that is the additional reserve to take into account other manufacturing errors, which can occur during machining that is especially important for the high-flexible fixtures. More precise evaluation of the exponents $m$ and $n$ can be obtained by increasing the number of experimental points.

5. Further research will be aimed to determination the dependences of fixture accuracy on the level of flexibility for the other fixture configurations for levers machining on the basis of the hypothesis, which is verified by the proposed mathematical model. The mathematical dependences for the other fixtures will be differing only by exponents $m$ and $n$.

\section{References and Notes}

[1] Karpus, V.E., Ivanov, V.O., Kotliar, O.V. et al. (2012). Intensification of Manufacturing Processes. Sumy State University, Sumy [in Ukrainian].

[2] Ivanov, V.O., Dehtiarov, I.M., Kushnirov, P.V. Patent of Ukraine № 71870. Adjustable Locating Module (2012) [in Ukrainian].

[3] Ivanov, V.O., Dehtiarov, I.M. Patent of Ukraine № 96399. Adjustable Locating Module (2015) [in Ukrainian].

[4] Ivanov, V.O., Karpus, V.E. Patent of Ukraine № 60130. Adjustable Locating Module (2011) [in Ukrainian].

[5] Ivanov, V.O., Karpus, V.E., Romanenko, I.V. Patent of Ukraine № 67918. Adjustable Locating Module (2012) [in Ukrainian].

[6] Ivanov, V.O., Karpus, V.E. Patent of Ukraine № 59745. Adjustable Locating Module (2011) [in Ukrainian].

[7] Karpus, V.E., Ivanov, V.O. Patent of Ukraine № 31416. Adjustable Locating V-block (2006) [in Ukrainian].

[8] Karpus, V.E., Ivanov, V.O. Patent of Ukraine № 30999. Adaptable Arbor (2006) [in Ukrainian].

[9] Ivanov, V.O., Dehtiarov, I.M. Patent of Ukraine № 95074. Adjustable Locating Module (2014) [in Ukrainian].

[10] Ivanov, V.O., Dehtiarov, I.M. Patent of Ukraine № 105296. Adjustable Locating Module (2016) [in Ukrainian].

[11] Karpus V.E. \& Ivanov V.A. (2012). Locating accuracy of shafts in V-blocks. Russian Engineering Research, 32 (2), 144-150.

[12] Karpus, V.E., Ivanov, V.O., Minenko D.O. \& Dehtiarov I.M. (2012). Rapid-Adjustable Locating Modules for Prismatic Parts. New Materials and Technologies in Metallurgy and Manufacturing, 2 (27), 91-94 [in Ukrainian].

[13] Sethi, A.K. \& Sethi, P.S. (1990). Flexibility in Manufacturing : A Survey. The International Journal of Flexible Manufacturing Systems, 2, 289-328.

[14] De Toni, A. \& Tonchia, S. (1998). Manufacturing flexibility: A literature review. International Journal of Production Research, 36 (6), 1587-1617.

[15] Shewchuk, J.P. \& Moodie, C.L. (1998). Definition and classification of manufacturing flexibility types and measures. International Journal of Flexible Manufacturing Systems, 10 (4), 325-349. 
[16] Parker, R.P. \& Wirth, A. (1999). Manufacturing flexibility: Measures and relationships. European Journal of Operational Research, 118 (3), 429-449.

[17] Terkaj, W., Tolio, T. \& Valente, A. (2009). A review on manufacturing flexibility. Design of flexible production systems: Methodologies and tools (pp. 41-61).

[18] Rogers, P.P., Ojha, D. \& White, R.E. (2011). Conceptualising complementarities in manufacturing flexibility: A comprehensive view. International Journal of Production Research, 49 (12), 3767-3793.

[19] Jain, A., Jain, P.K., Chan, F.T.S. \& Singh, S. (2013). A review on manufacturing flexibility. International Journal of Production Research, 51 (19), 5946-5970.

[20] Busch, J., Görke, M. \& Krämer, D. (2014). An approach to analyse the volume flexibility of production systems. doi: 10.4028/www.scientific.net/AMR.1018.605.

[21] Seebacher, G. \& Winkler, H. (2014). Evaluating flexibility in discrete manufacturing based on performance and efficiency. International Journal of Production Economics, 153, 340-351.

[22] Purvis, L., Gosling, J. \& Naim, M.M. (2014). The development of a lean, agile and leagile supply network taxonomy based on differing types of flexibility. International Journal of Production Economics, 151, 100-111.

[23] Yu, K., Cadeaux, J. \& Luo, B.N. (2015). Operational flexibility: Review and meta-analysis. International Journal of Production Economics, 169, 190-202.

[24] Balog, M. \& Husár, J. (2016). Methodical Framework of Flexibility Production Evaluation in Terms of Manufacturing Plant. Key Engineering Materials, 669, 568-577.

[25] Beach, R., Muhlemann, A.P., Price, D.H. et al. (2000). A review of manufacturing flexibility. European Journal of Operational Research,122, 41-57.

[26] Pérez Pérez, M., Serrano Bedia, A.M. \& López Fernández, M.C. (2016). A review of manufacturing flexibility: systematising the concept, International Journal of Production Research, 54, 3133-3148.

[27] Chambers, S. (1995). Flexibility in the Context of Manufacturing Strategy. Manufacturing Strategy: Process and Content. Chapman \& Hall, London, 283-295.

[28] Gaimon, C. \& Singhal, V. (1992). Flexibility and the choice of manufacturing facilities under short product life cycles. European Journal of Operational Research, 60, 211-223.

[29] Deshmukh, A., Talavage, J. \& Barash, M. (2002). Complexity in Manufacturing Systems. IIE Transactionon Manufacturing Systems, 30, 645-655.

[30] Calinescu, A., Sivadasan, S., Schirn, J. \& Huaccho, L. (2003). Complexity in Manufacturing: An Information Theoretic Approach. Technical Report, Manufacturing System Research Group, Department of Engineering Science, University of
Oxford, England.

[31] Correa, H.L. (1994). Linking Flexibility, Uncertainty and Variability in Manufacturing Systems: Managing Unplanned Change in the Automative Industry, Avebury, Gover Publishing, UK.

[32] Pelaez, J. \& Ruiz, J. (2004). Measuring Operational Flexibility. Technical Report, Faculty of Economy and Enterprise, University of Murcia, Spain

[33] Benjaafar, S. \& Ramakrishman, R. (1996). Modeling, measurement and evaluation of sequencing flexibility in manufacturing systems. International Journal of Production Research, 34, 1195-1220.

[34] Kaschel, H. \& Sánchez y Bernal, L.M. (2006). Importance of Flexibility in Manufacturing Systems. International Journal of Computers, Communications \& Control, 1 (2), 53-60.

[35] Kumbhar, N., Patil, G., Mohite, S. \& Sutar, M. (2012). Finite element modelling and analysis of workpiece-fixture system. International journal of Applied Research in Mechanical Engineering, 2 (2), 60-65.

[36] Papastathis, T.N. et al. (2012). Dynamics model of active fixturing systems for thin-walled parts under moving loads. International Journal of Advanced Manufacturing Technology, 9, 1233-1247.

[37] Tadich, B., Todorovich, P., Novkinich, B. et al. (2015). Fixture layout design based on a single surface clamping with local deformation. International Journal of Simulation Modelling, 3, 379-391.

[38] Kang, Y., Rong, Y. \& Yang, J.C. (2003). Computer-Aided Fixture Design Verification. Part 3. Stability Analysis. International Journal of Advanced Manufacturing Technology, 9, 842-849.

[39] Asante, J.N. (2010). Effect of Fixture Compliance and Cutting Conditions on Workpiece Stability International Journal of Advanced Manufacturing Technology, 48, 33-43.

[40] Wang, M.Y. (2002). Tolerance analysis for fixture layout design. Assembly Automation, 22, 153-162.

[41] Valandi, K., Vijaukumar, M. \& Kumar, K.S. (2014). Development, Fabrication and Analysis of Fixture. International Journal of Innovative Research in Science, Engineering and Technology, 3, 11414-11416.

[42] Ivanov, V.O., Dehtiarov, I.M., Karpus, V.E. Patent of Ukraine № 98925. Adjustable Locating-and-Clamping Module for Machining of Levers (2015) [in Ukrainian].

[43] Ivanov, V.O., Karpus, V.E., Dehtiarov, I.M. et al. (2015). Numerical Modeling of Fixtures for Machining of Levers. Bulletin of NTU "KhPI". Series: Technologies in mechanical engineering, 4 (1113), 110-115 [in Ukrainian]. 


\section{Biographical notes}

Assoc. Prof. Vitalii Ivanov, Ph.D., an Associate Professor of the Department of Manufacturing Engineering, Machines and Tools of Sumy State University (Ukraine). He received a B.S. Degree in Mechanical Engineering and Specialist Degree in Manufacturing Engineering from Sumy State University (Ukraine) in 2005 and 2006 respectively; an Ph.D. Degree in Manufacturing Engineering from National Technical University "Kharkiv Polytechnic Institute" (Ukraine) in 2010. In 2014 he was awarded the title of International Engineering Educator (ING.PAED. IGIP) by International Society for Engineering Education. Dr. Ivanov took part in research projects funded by Ministry of Education and Science of Ukraine, State Fund for Fundamental Researches (Ukraine), Ukrainian manufacturing companies, and EU grant program TEMPUS (project ENGITEC). Dr. Ivanov was a Visiting Scholar at Institute for Machine Tools, University of Stuttgart (Germany) in 2011, and Worcester Polytechnic Institute (USA) in 2013, and Visiting Associate Professor at Technical University of Kosice (Slovak Republic) in 2016. Dr. Ivanov is a member of ASME, IAENG, IGIP, and associate member of EuroScience. His research activities concern fixture design, include analysis, optimization, verification; CAFD/CAD/ CAE/CAPP/CAM methods in manufacturing engineering; engineering education. His works within this scope were published in textbooks, monographs, national and international journals and presented at many scientific conferences.

Ivan Dehtiarov, Ph.D. student of the Department of Manufacturing Engineering, Machines and Tools of Sumy State University (Ukraine). He received a Junior Specialist Degree in CNC machines and automatic lines from Sumy Machinebuilding College (Ukraine) in 2008; B.S. Degree in Mechanical Engineering and Specialist Degree in Manufacturing Engineering from Sumy State University (Ukraine) in 2010 and 2011 respectively. He took part in research projects funded by Ministry of Education and Science of Ukraine. I. Dehtiarov is a member of IAENG. His research activities concern fixture design, include analysis, optimization, verification; CAFD/CAD/CAE/CAPP/CAM methods in manufacturing engineering; CNC machining and programming. His works within this scope were published in national and international journals and presented at many scientific conferences.

Ivan Pavlenko, Ph.D., a Senior Lecturer of the Department of General Mechanics and Machine Dynamics of Sumy State University (Ukraine). He received a B.S. and M.S. Degrees in Dynamics and Strength from Sumy State University (Ukraine) in 2005 and 2006 respectively; an Ph.D. Degree in Dynamics and Strength of Machines from Sumy State University (Ukraine) in 2014. In 2014 he was awarded the title of International Engineering Educator (ING.PAED.IGIP) by International Society for Engineering Education. Dr. Pavlenko took part in research projects funded by Ministry of Education and Science of Ukraine (Ukraine) and Ukrainian manufacturing companies. Dr. Pavlenko was a Visiting Scholar at Institute of Power Machines and Equipment, Silesian University of Technology (Poland) during 2004-2008. Dr. Pavlenko is co-author of textbooks published within EU grant program TEMPUS (project ENGITEC) and co-author of the projects for improving the quality of higher engineering education. Dr. Pavlenko is a member of IAENG, IGIP, and associate member of EuroScience. His research activities concern the multidisciplinary investigations in the field of mechanical, manufacturing and petroleum engineering. Dr. Pavlenko is engaged in application of CAD/CAE methods and development of FEA. His research works were published in textbooks, national and international journals, and represented at many international conferences. 